\title{
FUNGSI XIANGQI BAGI MASYARAKAT TIONGHOA DI KOTA MEDAN
}

\author{
T. Kasa Rullah Adha, S.S., MTCSOL, Indah P Sari Haraha, S.S \\ Universitas Sumatera Utara, Medan \\ Email: notification@facebookmail.com
}

\begin{abstract}
ABSTRAK
Artikel ini meneliti fungsi catur gajah atau catur xiangqi bagi masyarakat Tionghoa di Kota Medan. Tujuan penelitian ini adalah untuk mengetahui keberadaan xiangqi di Yayasan Sad Putra Persada (YSPP) dan fungsi xiangqi bagi masyarakat Tionghoa di kota Medan. Artikel ini menggunakan teori Fungsionalisme Bronnislaw Malinowski.Metode yang digunakan adalah metode deskriptif dengan pendekatan kualitatif. Data dikumpulkan dengan melakukan observasi, wawancara dengan informan yang terkait dengan xiangqi, dan dari studi kepustakaan melalui buku, jurnal, tesis, dan website. Hasil dari penelitian ini menunjukkan: Fungsi xiangqi memiliki 5 fungsi yaitu, fungsi yang bertujuan sebagai sarana komunikasi, untuk meningkatkan konsentrasi, pengintegrasian masyarakat, untuk melatih kesabaran dan hiburan.
\end{abstract}

Kata Kunci :,Fungsi, Xiangqi

\begin{abstract}
The tittle of this articles is"The Existence and Function of Xiangqi for the Chinese Ethnic Group in Medan". The objective of the research was to find out the existence of xiangqi in Yayasan Sad Putra Persada (YSPP) and its function for the Chinese ethnic group in Medan. The research used the theory of Functionalism of Bronnislaw Malinowski. It used descriptive qualitative. The data were gathered by performing observation, interviews with informants who were related to xiangqi, and library studies from books, journals, thesis, and website. The result of the thesis shows that xiangqi in Yayasan Sad Putra Persada (YSPP) has last for 16 years, since 06 June 2000 up to present time. Xiangqi has five functions: to be used as communication facility, to increase concentration power, to integrate people, to exercise patience, and to be used as entertainment.
\end{abstract}

Keywords: Function, Xiangqi.

\section{PENDAHULUAN}

\subsection{Latar Belakang}

Kata kebudayaan berasal dari bahasa Sanskerta buddahyah, yaitu bentuk jamak dari buddhi yang berarti budi atau akal. Dengan demikian kebudayaan dapat diartikan hal-hal yang bersangkutan dengan akal (Koentjaraningrat, 2002:181). Adapun istilah culture, yang berasal dari 
kata Latin colere. Artinya mengolah atau mengerjakan, yaitu mengolah tanah atau bertani. Dari asal kata tersebut yaitu colere kemudian culture diartikan sebagai segala daya dan kegiatan manusia untuk mengolah dan mengubah alam (Soerjono Soekanto, 2003:172).

Salah satu kebudayaan Tionghoa yang menarik untuk diteliti adalah xiangqi. Xiangqi merupakan permainan tradisional asah otak yang dimainkan oleh dua orang dengan mengandalkan strategi khusus, dan sudah berkembang menjadi salah satu cabang olahraga yang berasal dari Tiongkok. Xiangqi dalam aksara Mandarin,terdiri dari kata 象 xiàngartinya gajah dan 棋 qí artinya catur, atau dapat disebut dengan catur gajah.

Xiangqi memiliki keunikan seperti terdapat pada buah catur yangberbentuk bulat. Setiap buah catur bertuliskan aksara Mandarin yang berkarakter sesuai peran dan mempunyai dua warna, yaitu hitam dan merah. Pada xiangqi terdapat buah catur yang tidak terdapat pada catur Internasional yaitu adanya buah catur yang bernama meriam.Selain itu, xiangqi memiliki keunikan tersendiri yaitu, memiliki papan yang di tengah-tengahnya terdapat sungai yang menandakan adanya perbatasan antara kedua buah catur hitam dan merah. Namun inti dari kedua permainan catur tersebut adalah sama, yaitu permainan asah otak yang menuntut konsentrasi tinggi dalam mengunci lawan dan akhirnya terkunci atau skakmat. Di kota Medan, keberadaan xiangqi dapat dikatakan sudah cukup lama, yaitu seiring masuknya etnis Tionghoa ke kota Medan. Akan tetapi permainan xiangqi ini dapat dikatakan belum begitu dikenal oleh masyarakat luas, terutama masyarakat non Tionghoa. Hal ini dapat dilihat dari yang memainkannya adalah sebagian besar dimainkan oleh etnis Tionghoa yang sudah berusia 40 tahun ke atas.

\subsection{Rumusan masalah}

Berdasarkan latar belakang masalah yang telah dikemukakan dan diuraikan pada pendahuluan di atas, maka penulis membuat rumusan masalah adalah : Bagaimana fungsi xiangqi bagi masyarakat Tionghoa di kota Medan

\subsection{Manfaat penelitian}

Secara teoritis, diharapkan penelitian ini dapat memberi wawasan baru kepada para pembaca fungsi xiangqi bagi masyarakat Tionghoa kota Medan. Hal tersebut juga dimaksudkan agar masyarakat dapat lebih menghargai dan memaknai benda tersebut sebagai suatu warisan budaya yang harus dijaga kelestariannya.

\subsection{Landasan teori}


Malinowski merintis bentuk kerangka teori baru untuk menganalisis fungsi kebudayaan manusia, yang disebutnya dengan teori fungsionalisme kebudayaan "a funitional theory of culture”. Menurut Malinowski (1984: 216) : “... Pada dasarnya kebutuhan manusia sama, baik itu kebutuhan yang bersifat biologis maupun yang bersifat psikologis dan kebudayaan pada pokoknya memenuhi kebutuhan tersebut. Kondisi pemenuhan kebutuhan yang tak terlepas dari sebuah proses dinamika perubahan ke arah konstruksi nilai-nilai yang disepakati bersama dalam sebuah masyarakat (dan bahkan proses yang dimaksud akan terus bereproduksi) dan dampak dari nilai tersebut pada akhirnya membentuk tindakan-tindakan yang terlembagakan dan dimaknai sendiri oleh masyarakat bersangkutan yang pada akhirnya memunculkan tradisi upacara perkawinan, tata cara dan lain sebagainya yang terlembaga untuk memenuhi kebutuhan biologis manusia tersebut”.

Hal inilah yang kemudian menguatkan tesis dari Malinowski yang sangat menekankan konsep fungsi dalam melihat kebudayaan. Ada tiga tingkatan oleh Malinowski yang harus terekayasa dalam kebudayaan yakni : “(1) Kebudayaan harus memenuhi kebutuhan biologis, seperti kebutuhan pangan dan prokreasi, (2) Kebudayaan harus memenuhi kebutuhan instrumental, seperti kebutuhan hukum dan pendidikan, (3) Kebudayaan harus memenuhi kebutuhan integratif, seperti kebutuhan agama dan kesenian".

Melalui tingkatan abstraksinya tersebut Malinowski kemudian mempertegas inti dari teorinya dengan mengasumsikan bahwa segala kegiatan / aktivitas manusia dalam unsur-unsur kebudayaan itu sebenarnya bermaksud memuaskan suatu rangkaian dari sejumlah kebutuhan naluri mahluk manusia yang berhubungan dengan seluruh kehidupannya.

Selanjutnya, Malinowski dalam (T.O. Ihroni 2006), mengajukan sebuah orientasi teori yang dinamakan fungsionalisme, yang beranggapan atau berasumsi bahwa semua unsur kebudayaan bermanfaat bagi masyarakat dimana unsur itu terdapat. Dengan kata lain, pandangan fungsionalisme terhadap kebudayaan mempertahankan bahwa setiap pola kelakuan yang sudah menjadi kebiasaan, setiap kepercayaan dan sikap yang merupakan bagian dari kebudayaan dalam suatu masyarakat, memenuhi beberapa fungsi mendasar dalam kebudayaan yang bersangkutan. Menurut Malinowski, fungsi dari satu unsur budaya adalah kemampuannya untuk memenuhi beberapa kebutuhan dasar atau beberapa kebutuhan yang timbul dari kebutuhan dasar yaitu kebutuhan sekunder dari para warga suatu masyarakat. Kebutuhan pokok adalah seperti makanan, reproduksi (melahirkan keturunan), merasa enak badan (bodily comfort), keamanan, kesantaian, 
gerak dan pertumbuhan. Beberapa aspek dari kebudayaan memenuhi kebutuhan-kebutuhan dasar itu. Dalam pemenuhan kebutuhan dasar itu, muncul kebutuhan jenis kedua (derived needs), kebutuhan sekunder yang harus juga dipenuhi oleh kebudayaan.

\section{A. Metode Penelitian}

Menurut Djajasudarma (1993:3), metode penelitian merupakan alat, prosedur, dan teknik yang dipilih dalam melaksanakan penelitian (dalam menggunakan data). Metode memiliki peran yang sangat penting, metode merupakan syarat atau langkah-langkah yang dilakukan dalam sebuah penelitian. Metode yang digunakan oleh penulis adalah metode deskriptif dengan pendekatan kualitatif.

Metode deskriptif kualitatif tidak berupa angka-angka, namun berupa data-data sesuai dengan fenomena yang terjadi dilapangan. Djajasudarma, (1993:16) berpendapat bahwa: “...Metode deskriptif kualitatif adalah data-data yang dikumpulkan bukanlah angka-angka, tetapi berupa kata-kata atau gambaran sesuatu. Semua yang dikumpulkan dapat menjadi kunci terhadap apa yang diteliti. Deskriptif merupakan gambaran ciri-ciri data secara akurat sesuai dengan sifat alamiah".

Data-data yang dikumpulkan oleh penulis berupa observasi, wawancara terhadap para informan yang terkait dengan pelestarian budaya permainan tradisional xiangqi, buku, jurnal, skripsi, dan website . Data digambarkan sesuai dengan hakikatnya dan disusun dengan baik sesuai keadaan.

\section{B. Pembahasan}

\subsection{Fungsi Xiangqi Bagi Masyarakat}

Pada pembahasan ini penulis akan membahas fungsi dari xiangqi bagi masyarakat Tionghoa di Kota Medan. Fungsi adalah kegunaan atau tujuan. Dalam Kamus Umum Bahasa Indonesia yang di tulis oleh W.J.S Poerwadarminta (1984:283) fungsi adalah pekerjaan yang dilakukan untuk mencapai tujuan.

\section{(1) Fungsi Sarana Komunikasi}

Xiangqi memiliki fungsi sebagai sarana komunikasi. Komunikasi merupakan suatu hal yang penting di dalam kehidupan, termasuk di dalam bermain xiangqi komunikasi merupakan satu komponen penting. Jika tidak terjalinnya komunikasi dengan baik, maka permainan tersebut juga tidak akan berjalan dengan lancar. Komunikasi yang dilakukan didalam bermain xiangqi adalah, terjalinnya komunikasi antara sesama pemain. Artinya melalui permainan xiangqi ini dapat 
terjalin komunikasi antara sesama etnis Tionghoa maupun non Tionghoa. Selain itu, melalui permainan ini juga dapat menjaga tali kekerabatan antar sesama warga Indonesia tanpa memandang etnis. Hal ini ditandai dengan berkumpul untuk bermain xiangqi, dan menciptakan suasana kekeluargaan. Hal ini dirasakan pada saat bermain mereka tidak hanya fokus pada permainan, tetapi juga saling berkomunikasi dan bercerita tentang berbagai hal.

\section{(2) Fungsi Meningkatkan Daya Konsentrasi}

Xiangqi berfungsi sebagai benda untuk meningkatkan daya konsentrasi. Xiangqi adalah salah satu permainan yang menggunakan pikiran dalammemainkannya. Dalam bermain xiangqi, para pecatur dituntut untuk fokus memainkannya, setiap langkah harus dipikirkan baik-baik agar dapat memperkirakan langkah selanjutnya yang akan diambil. Sekali saja salah dalam melangkah atau salah menyusun strategi pasti akan membuat semuanya menjadi berantakan, apalagi jika lawan sudah mulai menyerang dan mengacak-acak pola permainan. Hal ini menuntut agar pecatur lain keluar dari masalah yang diberikan lawan dan harus melakukan pola serangan yang mampu menyudutkan lawan.

Dalam bermain xiangqi harus menciptakan strategi-strategi atau taktik khusus, dan untuk menciptakan strategi dan taktik itu membutuhkan konsentrasi yang sangat mendalam. Tidak sedikit dari pecatur-pecatur tersebut yang sangat berkonsentrasi dalam permainan hingga tidak menghiraukan kondisi di luar dirinya. Misalnya saja pada pertandingan-pertandingan atau turnamen yang bertaraf nasional maupun internasional yang memperebutkan gelar atau mendapatkan hadiah lainnya, sehingga pecatur pasti memerlukan konsentrasi yang tinggi dalam memainkannya sehingga lawan kalah. Hal ini sangat bagus untuk melatih daya konsentrasi, fokus untuk mendominasi permainan, dan menciptakan jalan keluar dan menyelesaikan permainan tersebut.

\section{(3) Fungsi Pengintegrasian Masyarakat}

Xiangqi juga digunakan untuk menyatukan masyarakat sekitar. Hal ini dibuktikan dengan adanya pertandingan-pertandingan xiangqi, masyarakat sekitar tempat pertandingan xiangqi bersama-sama hadir dan melibatkan diri membantu terwujudnya pertandingan xiangqi tersebut. Hal ini terlihat dimana dalam pertandingan xiangqi pihak penyelenggara dan masyarakat sekitar yang melibatkan diri dalam pertandingan xiangqi. Ini terjadi karena adanya kerjasama dan kesatuan dengan para masyarakat sekitar tempat pertandingan xiangqi, karena jika tidak adanya kekompakan antara pihak penyelenggara dengan masyarakat sekitar pasti akan terjadi kekacauan 
diantara pendukung acara tersebut. Dengan demikian kehadiran xiangqi ini berfungsi sebagai benda pengintegrasian bagi individu-individu yang ada di dalamnya.

\section{(4) Fungsi Melatih Kesabaran}

Xiangqi berfungsi sebagai benda yang digunakan untuk melatih kesabaran. Xiangqi adalah olahraga untuk mengasah otak artinya di sini cara memainkannya adalah dengan menggunakan pikiran, tidak seperti halnya dengan olahraga lainnya yang menggunakan tenaga untuk memainkannya. Dalam bermain xiangqi yang paling utama adalah menggunakan otak atau berpikir untuk menyelesaikan permainan ini dan mengalahkan lawan dalam waktu singkat. Waktu yang digunakan dalam bermain xiangqi ini merupakan suatu komponen yang tidak penting, tidak ada batas waktu dalam permainan ini, yang terpenting adalah mengalahkan lawan dengan strategi tertentu sesuai peraturan permainan xiangqi yang telah ditetapkan.

Dibutuhkan waktu yang lama untuk memikirkan strategi atau langkah yang akan diambil untuk mengalahkan lawan, sehingga permainan ini akan memakan waktu yang lama. Untuk itu, dalam permainan ini dibutuhkan kesabaran agar tidak salah dalam menggambil langkah untuk mengalahkan lawan. Dalam hal ini, kesabaran merupakan salah satu kunci utama dalam bermain xiangqi, artinya sabar dalam melakukan tindakan, sabar dalam menyerang lawan, dan harus dipikirkan secara baik waktu yang tepat menyerang lawan. Sedikit saja salah menentukan langkah maka kemungkinan lawan akan dapat membalik keadaan sehingga membalik keadaan. Untuk memenangkan pertandingan ini seorang pecatur harus menjatuhkan bidak raja milik lawannya atau dengan kata lain skakmat, dengan menjatuhkan bidak raja milik lawan berarti permainan telah selesai dan permainan dimenangkan oleh pecatur yang berhasil menjatuhkan bidak raja milik lawannya.

\section{(5) Fungsi Hiburan}

Xiangqi juga berfungsi sebagai sarana hiburan, xiangqimampu mewujudkan suasana yang menceriakan lagi menghiburkan. Xiangqi dapat digunakan sebagai hiburan karena dapat menghibur masyarakat dan dapat memberi kesempatan untuk memperkenalkan xiangqi bagi masyarakat. Bermain xiangqi ini tidak hanya menciptakan suasana yang menegangkan karena dalam kondisi bertanding, tetapi juga ini menjadi sarana hiburan bagi orang-orang yang menyaksikan pertandingan tersebut. Mereka yang memainkan pertandingan tersebut tidak hanya memberikan hiburan bagi masyarakat luas, akan tetapi hiburan bagi diri mereka sendiri, karena dengan adanya pertandingan xiangqi ini, mereka dapat merasakan kepuasan tersendiri dalam 
memainkannya dan merasa ini dapat menjadi salah satu permainan yang dapat menyenangkan hati mereka, dan dapat merasa lebih gembira apabila berhasil memenangkan pertandingan.

Penenakan yang ketara terhadap aspek keceriaan ini menyebabkan semua yang terlibat dalam bermain permainan ini akan hadir perasaan gembira dan ceria. Perasaan gembira ini penting dalam kehidupan sehari-sehari karena ia merangkumi perasaan yang paling penting untuk mewujudkan kehidupan yang harmoni.

\section{SIMPULAN DAN SARAN}

\subsection{Simpulan}

Xiangqi adalah permainan yang sudah berubah menjadi salah satu cabang olahraga yang berasal dari Tiongkok. Pengertian xiangqi bila diterjemahkan ke dalam bahasa Indonesia memiliki arti gajah xiang dan catur qi. Jadi secara etimologis (bahasa) xiangqi bisa diartikan sebagai catur gajah.Dalam xiangqi kegiatan yang dilakukan adalah melatih kemampuan berpikir yang meliputi pikiran yang bertujuan untuk menyelesaikan permainan xiangqi.

Fungsi xiangqi bagi masyarakat Tionghhoa ada lima yaitu, xiangqi sebagai sarana komunikasi, xiangqi untuk meningkatkan daya konsentrasi,xiangqi sebagai pengintegrasian masyarakat, xiangqi untuk melatih kesabaran, dan xiangqi sebagai hiburan.

\subsection{Saran}

Xiangqi adalah salah satu permainan tradisonal yang berasal dari Tiongkok dan seiring berjalannya waktu xiangqi sudah menjadi cabang olahraga.Xiangqi merupakan salah satu contoh kebudayaan yang harus tetap dilestarikan keberadaannya baik dikalangan masyarakat Tionghoa maupun non Tionghoa dan dijaga walupun bukan asli dari kebudayaan Indonesia.Hal ini dirasakan penting karena xiangqi merupakan salah satu kebudayaan yang sudah lama berada di Indonesia dan bisa dikembangkan sebagai alat pemersatu bangsa tanpa memandang suku dan ras sebagaimana olahraga lainnya.

\section{DAFTAR PUSTAKA}

Bungin, Burhan. 2001. Metodologi Penelitian Sosial. Surabaya:Airlangga University Press.

Dediknas, 2007. Kamus Besar Bahasa Indonesia. Jakarta : Balai Pustaka.

Endarmoko, Eko. 2006. Tesaurus Bahasa Indonesia. Jakarta : Gramedia.

Djajasudarma,T.Fatimah. 1993. Metode Linguistik: Ancangan Metode Penelitian dan Kajian. Bandung: PT.Refika Aditama.

Hamidi. 2010. Metode Penelitian kualitatif. Malang: UMM Press. 
Hengky Frans dan Winardi Cristian. 2011. Analisa dan Perancangan Permainan Catur China Berbasis WEB. Jakarta: Universitas Bina Nusantara.

Ihroni, T.O. 2006. Pokok-pokok Antropologi Budaya. Jakarta : Yayasan Obor.

Koentjaraningrat.1970. Manusia dan Kebudayan di Indonesia. Jakarta: Djambatan.

Koentjaraningrat. 1991. Metode-metode Penelitian Masyarakat. Jakarta : PT. Gramedia Pustaka Utama.

Koentjaraningrat. 2009. Ilmu Antropologi. Jakarta: Rieneka Cipta.

Liushilan, 2003. Cong guoji xiangqi yu zhongguo xiangqi de yitong kan zhong xifang chayi.Chinese Academic Journal. Journal of wuhan Institute of Physical Education.

Malinowski, Bronislaw. 1960. A scientific Theory Of Culture. Chaprl Hill : University Of North Carolina Press. Nababan, P.W.J. 1984. Sosiolinguistik . Jakarta : PT. Gramedia Pustaka Utama.

Noveriansyah. 2008. Perkembangan xiangqi di Jakarta. Jakarta: Universitas Bina Nusantara.

Poerwanto, Hari. 2000. Kebudayaan dan Lingkungan dalam Prespektif Antropologi.Yogyakarta : Pustaka Pelajar Offset.

Ranjabar, Jocobus. 2006. SistemBudaya Indonesia. Bogor : Ghalia Indonesia.

Setiawan, Jefri. 2014. Perancangan Kampanye catur xiangqi untuk meningkatkan jiwa kepemimpinan dikalangan pelajar. Bandung: Universitas Kristen Maranatha.

Soehartono,Irawan.1995. Metode Penelitian Sosial. Bandung: PT.Remaja Rosdakarya.

Soekanto, Soerjono. 2003. Sosiologi Suatu Pengantar. Jakarta: Rajawali Pers.

Soemardjan, Selo. 1964. Setangkai Bunga Sosiologi. Edisi Pertama. Jakarta: Fakultas Ekonomi Universitas Indonesia.

Sudaryanto. 1993. Metode dan Aneka Teknik Analisis Bahasa. Yogyakarta: Duta Wacana University Press.

Wang, XudanZhen. 2007. zhonguo xiangqi yu guoji xiangqi bijaio fenxi. Chinese academic journal electronic Journal of Chongqing Institute of Technology.

Yuzhihui. 2012. zhonghua zhuantong wenhua jingdian.minjian youxi. huangshan: huangshan shushe.

\section{Data Penulis}

Penulis 1

Nama

: T. Kasa Rullah Adha, S.S., MTCSOL

Prodi

: Sastra Cina

Perguruan Tinggi : Universitas Sumatera Utara

Nomor HP : 081932352189

Email : nuoni.zf@gmail.com

Penulis 2

Nama

Prodi

: Indah P Sari Haraha, S.S

Perguruan Tinggi : Universitas Sumatera Utara

Email

: Email: notification@facebookmail.com 